\title{
Del entrampamiento perfecto a la transformación de El Salvador en la primera mitad del siglo XXI
}

Alberto Arene

Economísta, asesor de la rectoria y miembro del Senado Consultivo de la UTEC.

\section{Introducción}

U n sentimiento cada vez más generalizado de pesimismo, incertidumbre e impotencia se ha apoderado de los salvadoreños en los últimos años. Algunos de los factores que lo explican son: el deterioro de la situación económicosocial y la ausencia de un horizonte de certidumbre y progreso; los altísimos niveles de criminalidad e impunidad diversa; y el conocimiento ciudadano de la mediocridad, corrupción y falta de talante democrático y modernizador de una buena parte del liderazgo de la irreformable partidocracia.

La situación que hoy vivimos es producto de los efectos económicos y sociales acumulados de la guerra (1980-1991) y de la instalación del modelo patrimonialista/neoliberal en el ámbito político-institucional y económico-social en la postguerra (1991-2009). Este se caracterizó por un decreciente crecimiento económico y una limitada integración social que insertó al país a la globalización, al revés, "exportando" mucha gente, importando muchos bienes y servicios, y exportando muy pocos. Una economía cada vez mas incapaz de producir, redistribuir riqueza y crecer y un sistema político fueron incapaces de realizar las reformas para profundizar y consolidar la democracia y desarrollar la institucionalidad.
Es este modelo el que nos llevó a la crisis actual, agudizada por los efectos de la crisis económica internacional. Es este modelo el que está históricamente agotado.

Por eso afirmamos que la problemática que enfrentamos es de naturaleza estructural, y su superación depende, prioritariamente, de una nueva visión y una estrategia de desarrollo que sean capaces de generar un gran respaldo y fuerza nacional con gran apoyo regional e internacional, para su progresiva implantación. Esto tomará muchos años y una enorme determinación y constancia de las fuerzas democráticoprogresistas y de la modernidad. Pero debemos comenzar, y avanzar sin tregua ni pausa hasta que volvamos realidad una nación democrática, segura, próspera y solidaria que vea su futuro con alegría y confianza.

Ser territorialmente pequeños no nos obliga ni compromete a seguir pensando y actuando en pequeño. Debemos pensar y actuar en grande.

\section{Antecedentes históricos}

Un siglo duró aproximadamente el llamado capitalismo oligárquico salvadoreño (1880-1980). Surgió a partir de una ma- 


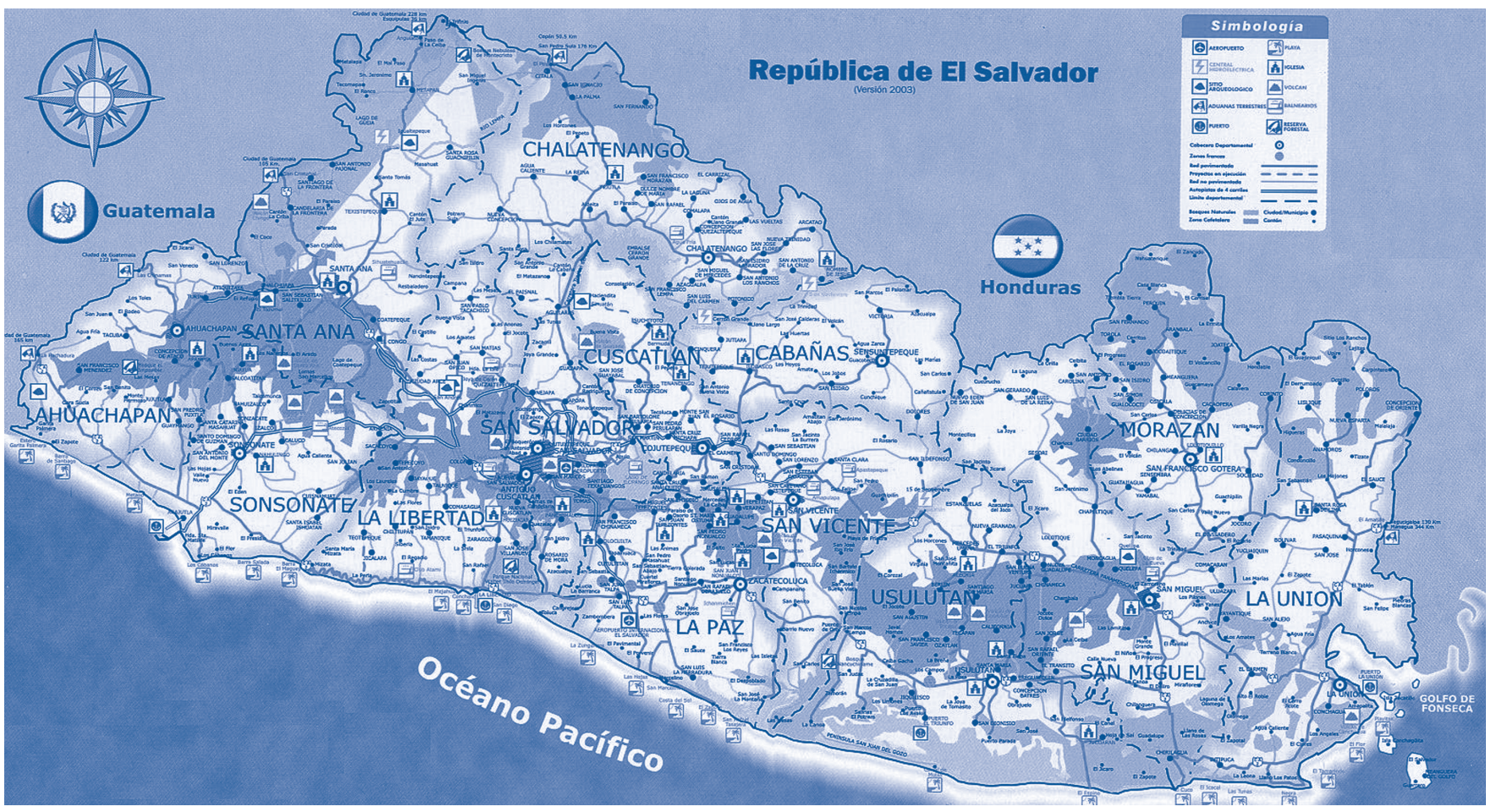

triz monoproductora-exportadora del café, el último cuarto del siglo XIX, consolidándose en el primer cuarto del siglo $X X$, conformando con la dictadura militar, hasta finales de los 40, una auténtica "República cafetalera".

Dicho modelo se transformó en las tres décadas siguientes (1950-1970) con la diversificación del modelo agroexportador (café, algodón, caña de azúcar, camarones) y con el impulso de un modelo de industrialización ligera de bienes de consumo, posibilitando altas de crecimiento y el surgimiento de las clases medias urbanas. Dicha industrialización fue posible con la creación del Mercado Común Centroamericano que dio lugar a una suma de pequeños mercados en expansión protegidos por un arancel común subregional, estimulando y viabilizando un proceso de industrialización sustitutiva de importaciones en los mercados nacionales, y de exportaciones a los mercados centroamericanos primero y al exterior después.

Este modelo económico se desmanteló progresivamente en las siguientes tres décadas (1980-2010). Primero en los 80 con la reforma agraria y la nacionalización de la banca y del comercio exterior, las guerras y las crisis prolongadas en El Salvador y el CA-4. Luego, con la llegada de Arena al poder liderado por un grupo empresarial modernizante, que impulsó en los 90 un nuevo modelo de liberalización de mercados y privatizaciones de la banca, los seguros, el sistema de pensiones, las telecomunicaciones y la distribución de la energía eléctrica, cuyas compañías desarrollaron nacional y regionalmente, vendiéndolas a grupos extranjeros en la primera década del siglo XXI.

Un nuevo modelo económico, liderado en sus inicios por Fusades, y la reforma política e institucional resultante de los acuerdos de paz fueron los dos ejes del proyecto políticoeconómico hegemónico en El Salvador en las últimas dos décadas. Pero este proyecto no se implantó consistente y sostenidamente según el diseño original de Fusades apoyado por el Dr. Harberger, de la Universidad de Chicago, quién propuso un modelo de crecimiento liderado por las exportaciones. Su ejecución específica en los tres primeros gobiernos de Arena fue determinada considerablemente por los 
intereses particulares del grupo empresarial modernizante liderado por el empresario y presidente del primer Gobierno de Arenero, Alfredo Cristiani.

El modelo y/o esquema económico específico que se impuso y ejecutó se agotó progresivamente a partir de 1997: 1) con el prolongado estancamiento del crecimiento económico, con una macroeconomía estructuralmente desequilibrada y desestabilizada -déficits comercial y fiscal y deuda pública en los límites superiores- y un régimen dolarizado que congeló el tipo de cambio, eliminando la autoridad y política monetaria; y 2) con el estancamiento e involución política/ institucional prolongados, desde que se implantaron la primera generación de reformas resultantes de los acuerdos de paz (1992-1996).

Adicionalmente, los efectos de la crisis económico-financiera internacional, la llegada de la izquierda al gobierno en el 2009, la crisis y división de la derecha y la profunda recomposición política en curso terminaron de darle el golpe de gracia al modelo llamado neoliberal, ejecutado bajo una impecable lógica patrimonialista, agotándose progresivamente el modelo/esquema económico gestionado en las últimas dos décadas.

\section{La globalización y la centroamérica de dos velocidades}

Con los acuerdos de paz finalizaron las guerras y se fundaron las democracias por primera vez en la historia de Guatemala, Honduras, El Salvador y Nicaragua (CA-4), coincidiendo la post guerra fría y la globalización de los 90 con la profundización de la ofensiva neoliberal iniciada en los 80 en Latinoamérica.

Durante las guerras y la crisis de 1979 a 1990, el Producto interno bruto (PIB) per cápita se redujo 20\% en el CA-4, mientras en Costa Rica y Panamá, sin guerras, se redujo 6\%. De 1991 al 2010 el CA-4 creció solo 34.1\%, mientras Costa Rica y Panamá crecieron 80\%. En el 2010 el PIB per cápita del CA-4 fue solo 5.8\% mayor al de 1978 -el máximo nivel de la pre-guerramientras el de Costa Rica y Panamá fue 78\% mayor. Fue en el período de paz y democracia que la Centroamérica del sur dejó muy atrás a la del norte, profundizándose la Centroamérica de dos velocidades. Su inserción diferente a la globalización en las últimas dos décadas explicaría semejante brecha.

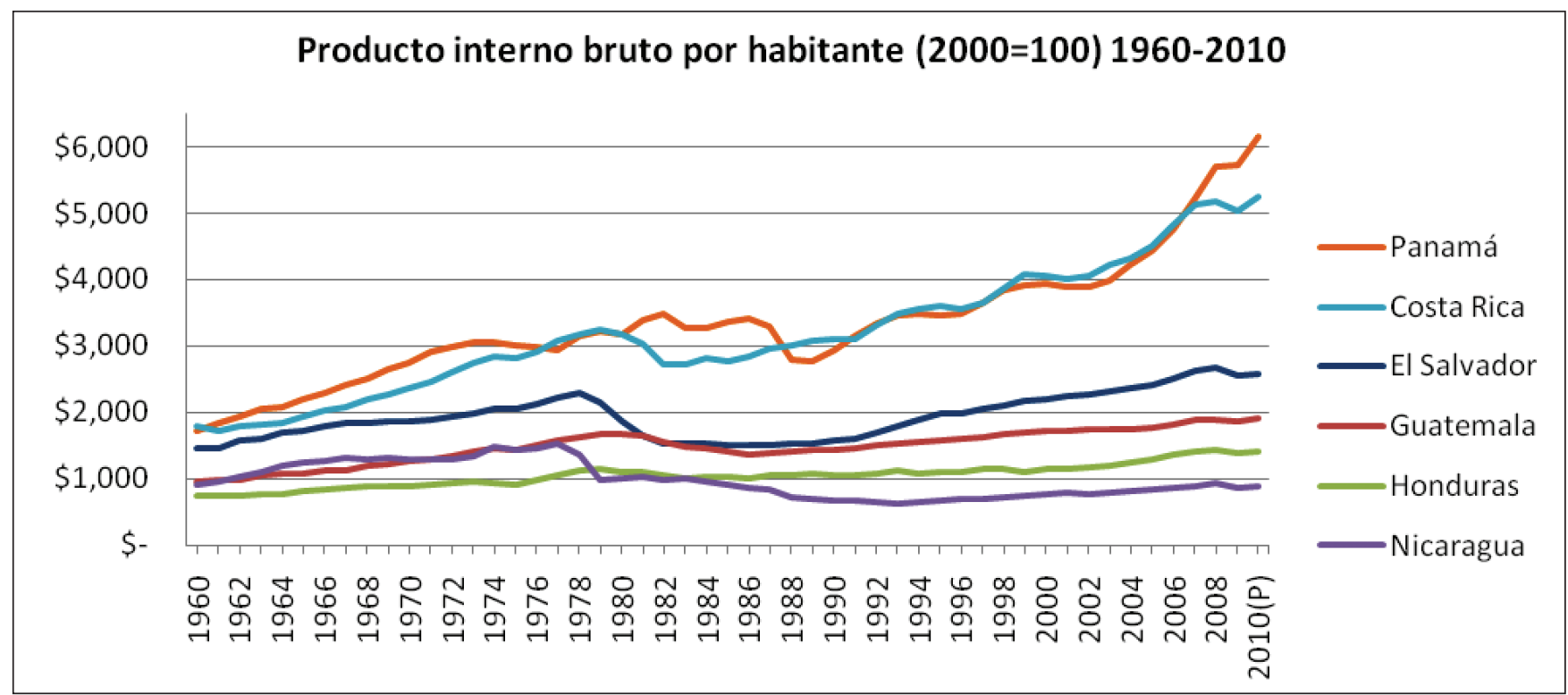

Fuente: Elaboración propia con base a datos del Banco Mundial. 
La nueva recomposición geopolítica y geoeconómica transformó radicalmente el contexto estratégico internacional. El capitalismo global, la liberalización y la apertura de las economías de mercado, la exacerbación de la competencia y la conformación de grandes bloques económico-comerciales en el marco de un nuevo orden hegemónico internacional democrático-conservador, tenderían a ser, en adelante, referentes determinantes de una nueva época histórica con un proceso de creación y concentración acelerada de riqueza a escala global.

Paralela y sinérgicamente la revolución científico-tecnológica y la nueva era digital y de las comunicaciones, en la llamada aldea global abrieron un profundo cambio civilizatorio, un cambio de época que transformó progresiva e irreversiblemente el funcionamiento societal a escala mundial.

Las dos décadas de la postguerra en Centroamérica (19902009) donde se implantaron las reformas para desarrollar la democracia y liberalizar y abrir las economías, coinciden con las dos décadas de las mayores y mas diversas transformaciones comprimidas de la historia de la humanidad: 1) La caída del socialismo real y la desintegración de la órbita soviética; 2) La conformación de los grandes bloques geopolíticos y económicos-comerciales (la Unión Europea, el bloque norteamericano, el Asean); 3) El resurgimiento de la democracia y de los derechos humanos como referente político fundamental; 4) El desarrollo de la era de la globalización, la revolución científico-tecnológica y la sociedad del conocimiento; 5) La liberalización e internacionalización de las inversiones y el comercio acompañados del boom del transporte aéreo y marítimo; 6) La emergencia de China y de la India como potencias económicas, que con los tigres asiá- ticos conforman el eje económico de mayor crecimiento en la economía, el comercio y el transporte mundial.

Dichas transformaciones científico-tecnológicas, geoeconómico-comerciales y geopolíticas, y la nueva configuración del poder económico y político-institucional resultante, pasaron a constituir el centro motor de las transformaciones a escala mundial, determinando los espacios y oportunidades de las grandes naciones, y de las medianas y pequeñas naciones de la periferia del sistema mundial, las centroamericanas incluidas. Aquellas naciones que no logren insertarse inteligentemente y saquen el máximo provecho de dichas transformaciones, fortaleciendo la democracia y la institucionalidad y creando competitiva y sostenidamente riqueza, y distribuyéndola mucho más equitativamente, someterían a sus pueblos a la pobreza, a la división, a la confrontación, a la violencia y a la irrelevancia crecientes, caldo de cultivo del crimen organizado, del narcotráfico internacional y de Ios radicalismos y populismos de cualquier signo. La historia nos enseña que "una vez la gente es desprovista de la esperanza de una mejor vida para ellos y sus hijos, las sociedades basadas en el consenso muy probablemente fracasarán."1

Con la crisis financiera y económica internacional y sus efectos mundiales concluye un ciclo histórico internacional de tres décadas de hegemonía conservadora con grandes consecuencias para el mundo y Centroamérica: 1) El orden neoliberal de las últimas tres décadas ha sido cuestionado internacionalmente, y un nuevo consenso estaría surgiendo en torno al imperativo de una mayor regulación de los mercados financieros y un papel fortalecido del Estado y de sus instituciones nacionales e internacionales en el desarroIlo. La inclusión social y la lucha contra la pobreza vuelve a

${ }^{1}$ Martin Wolf, prefacio al libro Why Globalization Works. The Case for a Global Market Economy, Yale University Press, 2005. 
estar en el primer lugar de la agenda internacional en general, y de los países centroamericanos en particular, los más desiguales en Latinoamérica, el continente mas desigual del mundo. 2) Costa Rica y Panamá han entrado en una etapa de mayor aprovechamiento de la globalización para profundizar sus modelos de desarrollo, siendo sus índices de desarrollo humano y sus perspectivas de crecimiento mucho más alentadores. 3) Guatemala, Honduras, Nicaragua y El Salvador, cada uno con sus particularidades, experimentan prolongados deterioros político-institucionales y estancamientos económico-sociales, identificándose claramente una Centroamérica de dos velocidades: "Hay una Centroamérica de dos velocidades: una al sur que crece y avanza con mayor claridad de propósitos (Costa Rica y Panamá), y otra al norte del río San Juan, lerda y empantanada, que no acaba de definir rumbo y apuesta estratégica (Guatemala, Honduras, El Salvador y Nicaragua)..."2 4) Un nuevo "paradigma" y eje latinoamericano de gobiernos impulsa, desde el poder, un nueva "opción de desarrollo y emancipación de los pueblos" con el llamado "socialismo del siglo XXI", con estrategias específicas de implantación en Nicaragua, Honduras y El Salvador, sacando provecho del agotamiento histórico del modelo político-institucional y económico-social de las últimas dos décadas.

Mientras el CA-4 se insertó a la globalización al revés, "exportando" mucha gente y pocos bienes y servicios, costa Rica y Panamá hicieron lo contrario, habiendo creado las condiciones para que esto fuera posible. Es imperativo la transformación del agotado modelo político-institucional y económico-social de la post guerra en Guatemala, Honduras, El Salvador y Nicaragua.

\section{El agotamiento del modelo económico- social y político-institucional de la post- guerra en El Salvador}

En su dimensión político-institucional, tal modelo se centró en la desmilitarización de la sociedad y la supeditación de las Fuerza Armada al poder civil, así como en la garantía formal de los derechos humanos, civiles y políticos. Pero no avanzó en los derechos económicos y sociales, en la promoción y fortalecimiento de la cultura democrática, ni en las reformas político-institucionales de segunda generación, que habrían priorizado la transformación del Órgano Judicial, del Ministerio Público, de la Corte de Cuentas y del sistema de partidos políticos, cuyo anquilosamiento está en el origen de la debilidad institucional que padecemos. Los partidos políticos en El Salvador, y en particular en el CA-4 en general, son el eslabón más débil de la democracia y el origen último de la debilidad del resto de instituciones democráticas. ${ }^{3}$ Como es conocido en el análisis de sistemas, un sistema es tan fuerte como lo es su eslabón más débil.

En su dimensión económico-social, el modelo de la post guerra fue de baja inversión y lento crecimiento, impulsado no por la producción y las exportaciones, sino por el consumo y las importaciones financiados por remesas familiares crecientes a partir del éxodo de más de dos millones de salvadoreños que, desde el inicio de los 80 , salieron hacia Estados Unidos, Canadá, Australia y otros países, producto de la guerra y de la falta de oportunidades. Las migraciones y las remesas familiares, además de equilibrar las cuentas externas y paliar los déficits de la economía familiar, fueron la principal fuente de movilidad social, ocultando así la ausencia tanto de una política productiva-exportadora como de una verdadera política social.

\footnotetext{
2 Roberto Rubio, "La Centroamérica de dos velocidades", La Prensa Gráfica, 8 de marzo, 2010

3 El término "el eslabón más débil" fue tomado de Thomas Carothers, "Confronting the Weakest Link. Aiding Political Parties in New Democracies". Carnegie Endowment for International Peace.Washington D.C. 2006.
} 
De esta manera, la inserción a la globalización de El Salvador promovida por este modelo ha sido considerablemente improductiva, pues no se basa en el estímulo y promoción de inversiones nacionales y extranjeras para incrementar sostenidamente la producción y exportación de bienes y servicios diversos, sino en la "exportación" masiva de gente y en la importación masiva de bienes y servicios.

Así, sin estrategia de desarrollo productivo-exportador y de incorporación del progreso técnico, los diversos tratados de libre comercio han disparado el déficit comercial, sin que se atrajese inversión y tecnología extranjeras para fortalecer la base productiva y exportadora nacional, crear empleos de mejor calidad y generar y multiplicar ingresos diversos.

Los resultados son contundentes: ${ }^{4}$ 1) Crecimiento económico lento y decreciente: de un crecimiento anual de $2,6 \%$ del PIB per cápita en los 90, a un crecimiento de solo 1,7\% anual en la primera década del 2000. En el 2010, el PIB per cápita de El Salvador fue apenas 15 \% mayor que el nivel histórico máximo previo a la guerra (1978).

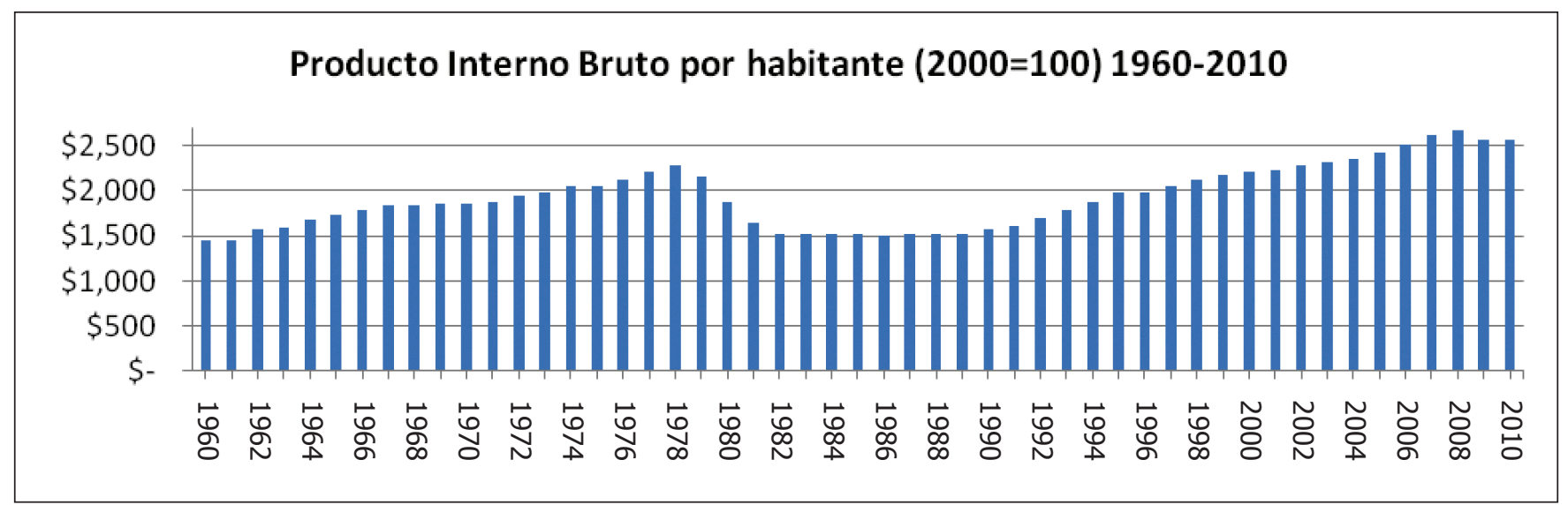

Fuente: Elaboración propia con base a datos del Banco Mundial.

2) Crecimiento del Consumo mayor que la Producción: La producción fué mayor que el consumo entre 1\% y $5 \%$ de 1990 a 1998, decreciendo desde entonces hasta equilibrarse en el 2003-2004. Desde entonces el consumo superó a la producción en $2.4 \%$ en el 2005, 3.7\% en el 2006, 6.1\% en el 2007 y 7.6\% en el 2008 consolidándose un patrón de crecimiento del consumo mayor que la producción.

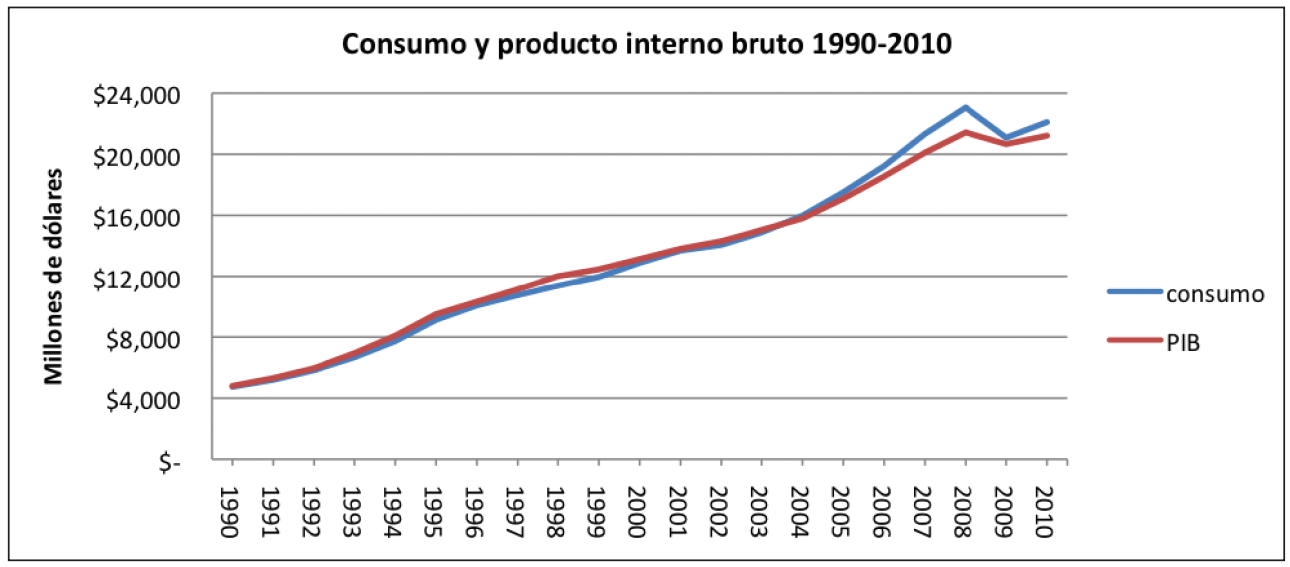

Fuente: Elaboración propia con base a datos del Banco Central de Reserva.

\footnotetext{
${ }^{4}$ Los datos presentados a continuación incluyen la más reciente actuzalización presentada por el presidente del Banco Central de Reserva el 7 de Abril del 2011.
} 
3) Creciente déficit comercial: de un déficit anual de 10,6\% del PIB en los 90 a un déficit del 18\% del PIB en la década del 2000 (18\% en el 2008; $23 \%$ en el 2009; $17,5 \%$ en el 2010 ).

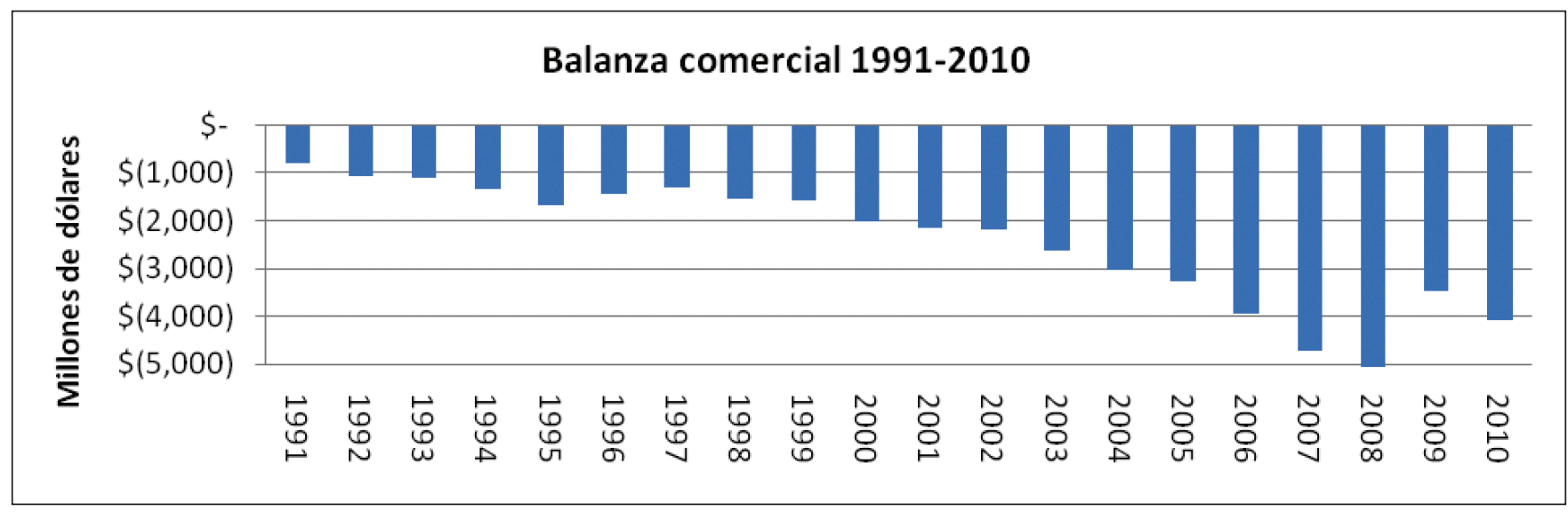

Fuente: Elaboración propia con base de datos del Banco Central de Reserva.

4) Creciente déficit fiscal: de un déficit anual de 1,8\% del PIB en los 90 a un déficit de 3,4\% del PIB en los 2000 (alcanzando $5,6 \%$ el 2009 y $4,2 \%$ en el 2010).

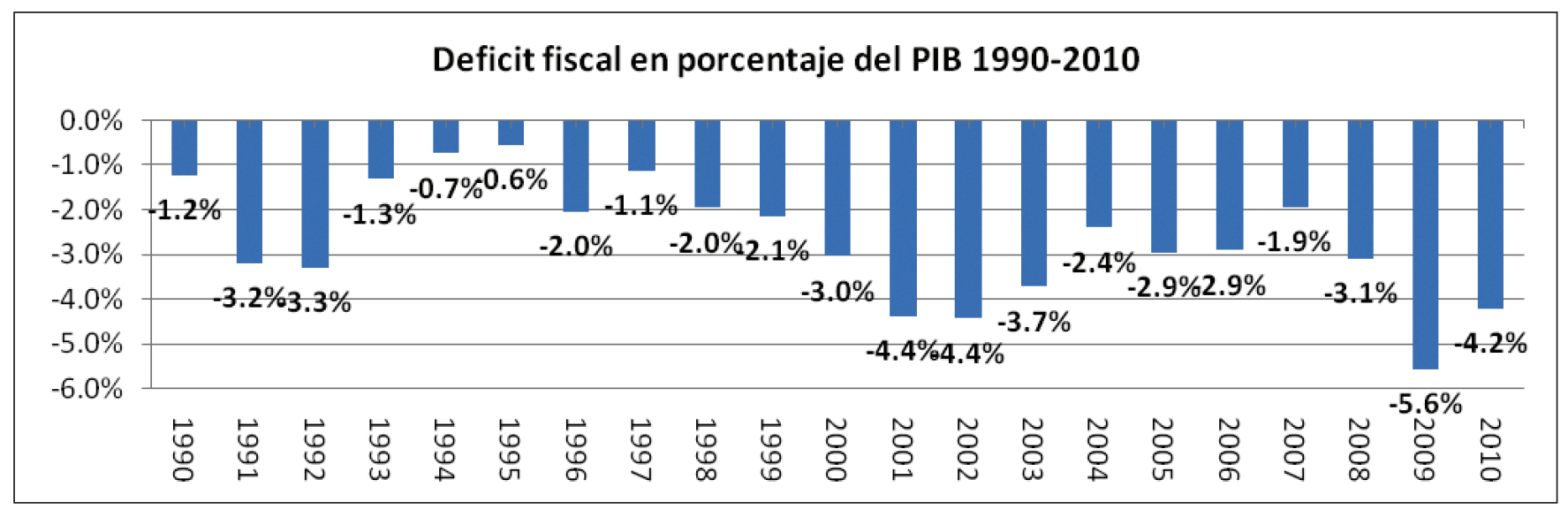

Fuente: Elaboración propia con base de datos del Ministerio de Hacienda. 
5) Creciente endeudamiento público: del 59\% del PIB en 1991 al 33\% en el 1998; 53\% el 2009 y 56\% en el 2010, nivel de endeudamiento que tiende a aumentar y aproximarse al nivel que tuvimos al finalizar la guerra.

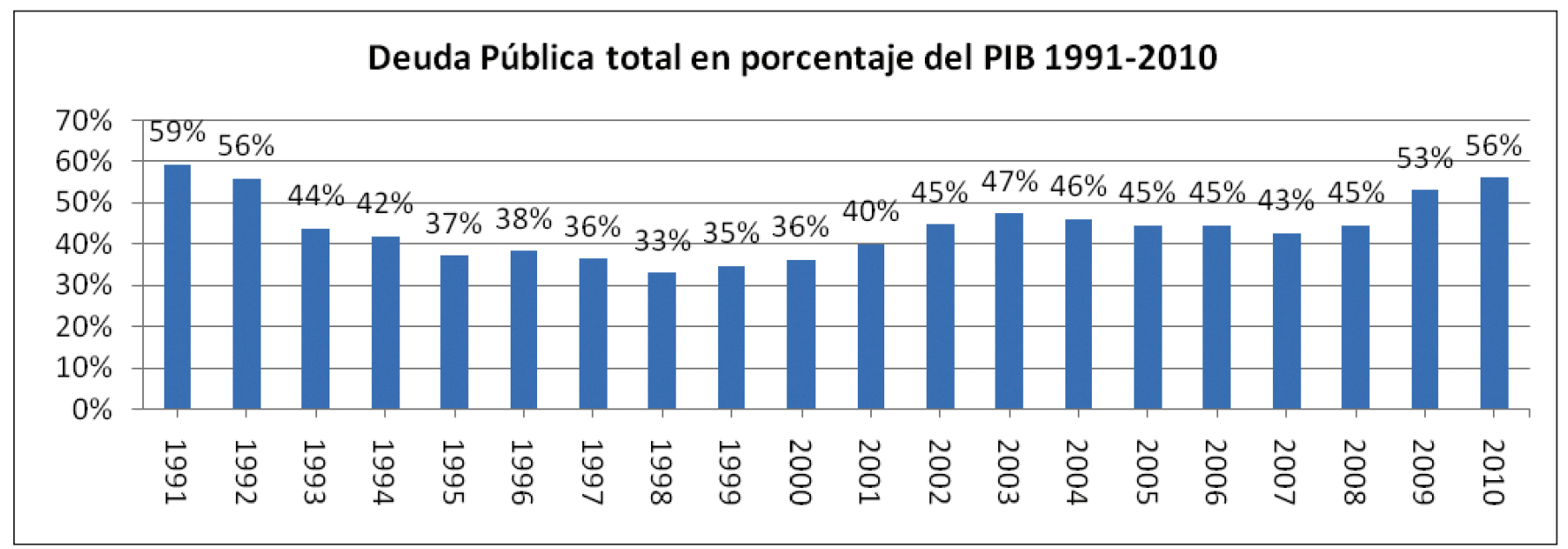

Fuente: Elaboración propia con base de datos del Ministerio de Hacienda.

6) Los salarios mínimos reales, al finalizar la década de los 2000 son equivalentes a los de principios de la década de los 90.

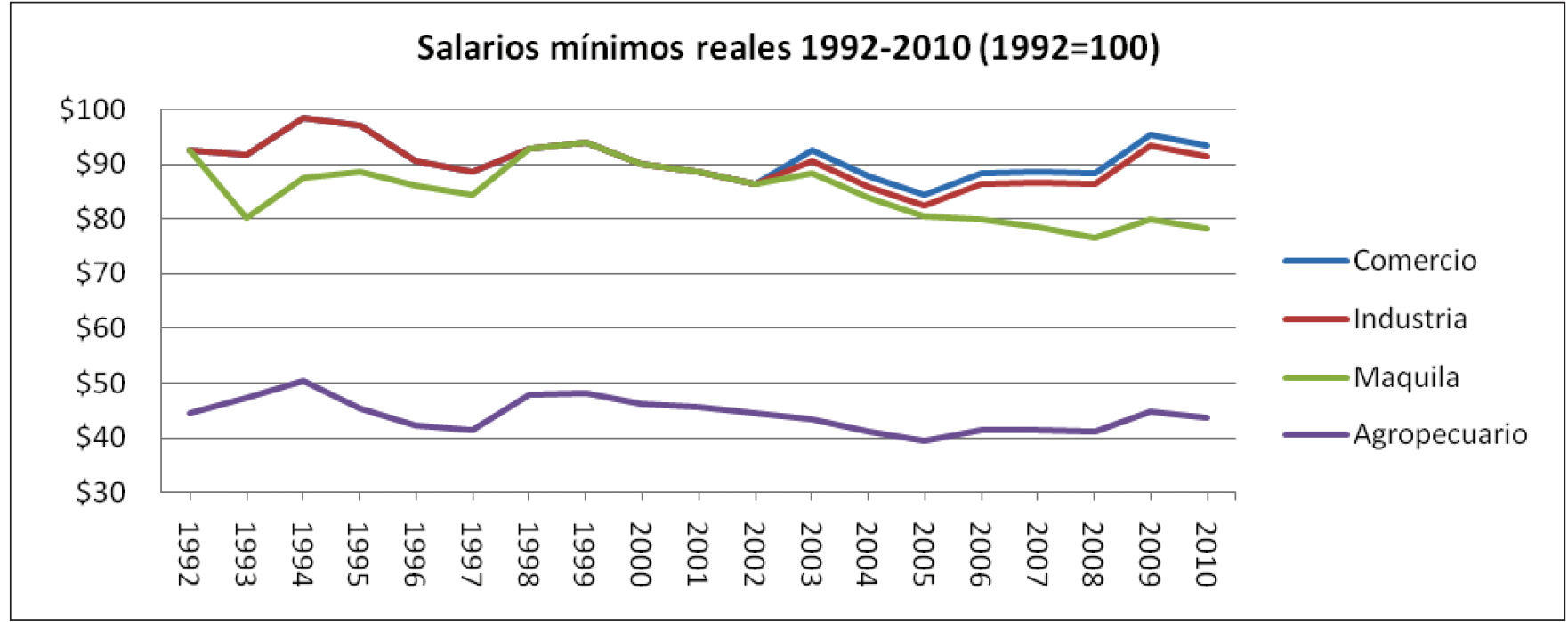

Fuente: Elaboración propia con base de datos de la Digestyc y del Ministerio de Economía.

No obstante el bajo crecimiento promedio de la economía y una débil política social, la pobreza se redujo de $59 \%$ en 1990 a $37,8 \%$ en el 2009, lo que se explica principalmente por las migraciones de dos millones de salvadoreños y 40 mil millones de dólares, aproximadamente, de remesas familiares en las últimas dos décadas. Las remesas familiares, además de equilibrar las cuentas externas y paliar los déficits de la economía familiar, fueron la principal fuente de movilidad social, ocultando la ausencia de una política productiva-exportadora y de una verdadera política social. 


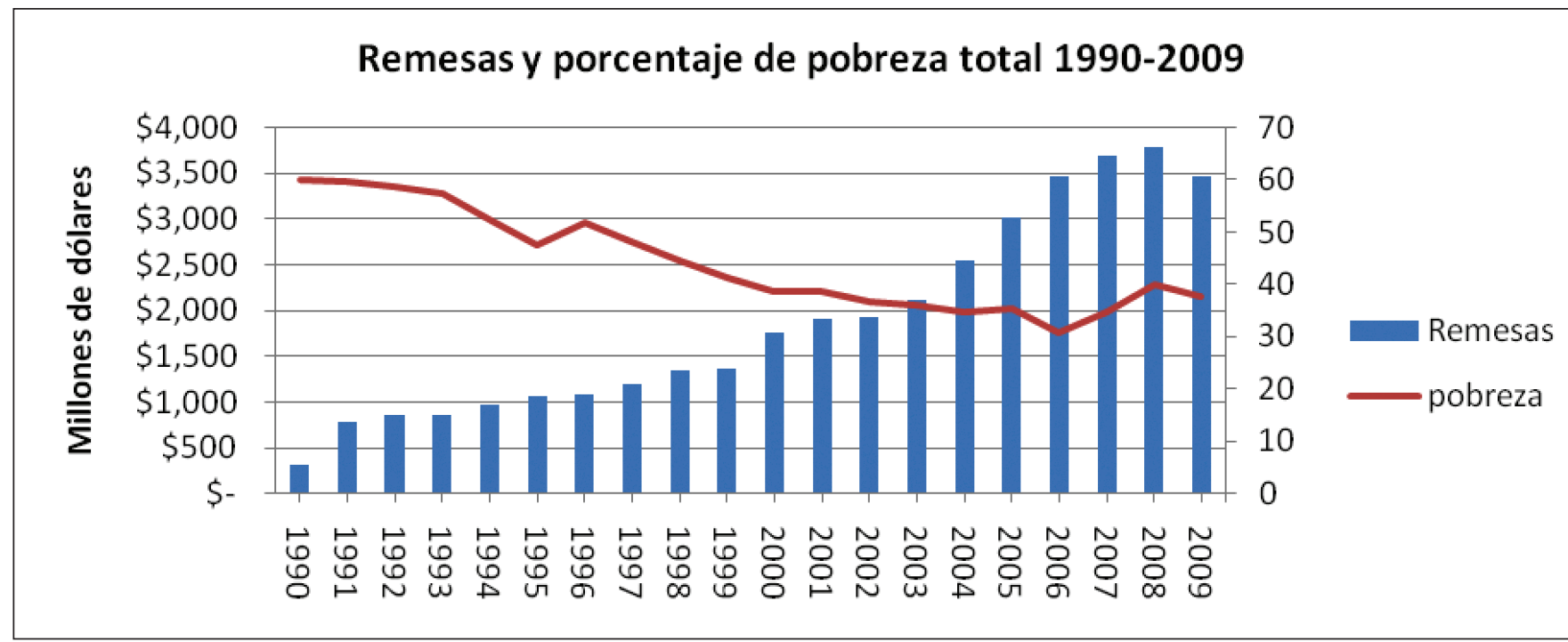

Fuente: Elaboración propia con base de datos del BCR y EHPM.

De esta manera, la inserción a la globalización de El Salvador promovida por este modelo ha sido improductiva, pues no se basa en el estímulo y promoción de inversiones nacionales y extranjeras para incrementar sostenidamente la producción y la exportación de bienes y servicios diversos, sino en la "exportación" masiva de gente y la importación masiva de bienes y servicios. Es un modelo de inserción al revés, que ha "exportado" mucha gente, importado muchos bienes y servicios y exportado relativamente pocos.

Sin motores del crecimiento, con grandes desequilibrios macroeconómicos, endeudamiento público altos y crecientes, el agotamiento del modelo nos ha conducido a la crisis estructural actual, que se agravará aún más por la disminución irreversible de las migraciones y de las remesas, y por la crisis fiscal del Estado. Bajo el modelo actual, el Estado ya no puede hacer frente ni a las obligaciones mínimas de la deuda pública, social, medioambiental y de infraestructura ni a futuros y probables desastres naturales y crisis económicofinancieras internacionales.

Ningún país puede subsistir ni desarrollarse consumiendo más de lo que produce, exportando pocos bienes y servicios e importando casi todo con los ingresos del éxodo masivo de su gente. Aún menos cuando las remesas son irreversiblemente decrecientes. Este es el caso de El Salvador y también del CA-4.

La situación nacional es de una complejidad mucho mayor de lo que una buena parte del liderazgo nacional comprende o está dispuesto a aceptar. El agotamiento histórico del modelo político-institucional y económico-social de las últimas dos décadas ha generado y explica esta crisis estructural. Entiéndase: el modelo de la post guerra ya no da para más.

La situación nacional solo podrá mejorar sustancialmente cuando se instale una nueva visión y estrategia de desarrollo de la nación de mediano y largo plazo que pueda, competitiva y sostenidamente, crear riqueza y distribuirla mejor, asegurando la gobernabilidad democrática y la seguridad pública, impulsando para ello, sin tregua ni pausa, las reformas estructurales que sean necesarias. Esto requiere de una nueva mayoría política y social capaz de impulsar un nuevo consenso estratégico nacional para la prosperidad y la gobernabilidad democrática sostenida. 


\section{La herencia que recibió el Gobierno de Funes: el entrampamiento perfecto}

Cuando Mauricio Funes fue electo presidente de la República el 15 de marzo de 2009 -después de veinte años consecutivos de gobiernos de Arena-, la situación del país estaba muy deteriorada. La crisis financiera internacional había golpeado severamente estructuras económicas, sociales, de seguridad e institucionales muy precarias, afectando más fuertemente a El Salvador que al resto de países latinoamericanos, solo después de México, configurándose la tormenta perfecta. Desde entonces comenzó a enfrentar la severa crisis económica, social y de seguridad con limitados recursos financieros e institucionales y las mayores expectativas históricas de cambio: el entrampamiento perfecto.

En mayo de 2009, el gobierno saliente y el entrante, acordaron un plan financiero de $\$ 2,753.5$ millones de dólares que aprobó la Asamblea Legislativa, \$950 millones provenientes de organismos multilaterales financieros y $\$ 1.803 .5$ millones de la emisión y colocación de bonos. De los \$950, 650 se reorientaron para apoyo presupuestario, incluidos 200 para financiar necesidades urgentes de caja, y \$300 para proyectos de inversión social, mientras los \$1.803.5 millones de dólares restantes sirvieron para reestructurar la deuda de corto a largo plazo (\$800 millones, para el pago anticipado o vencido de la deuda de los Eurobonos (\$653.5millones, para cancelar los certificados fiduciarios de educación, paz social y seguridad ciudadana emitidos en el 2007 (\$183 millones y para completar las inversiones de obras en educación y seguridad pública no cubiertas con dicho fideicomiso (\$167 millones. La deuda pública neta en el 2009 se incrementó sustancialmente, pero mejoró su perfil financiero, disminuyendo sus tasas de interés y transformando las tasas variables en fijas, y aumentando el período de vencimiento.

Sin autoridad ni política monetaria y una banca de fomento reducida a su mínima expresión, con una banca privada sin otorgar créditos para la actividad económica, la productiva en particular, el nuevo gobierno tuvo limitados recursos y herramientas para enfrentar semejante caída de los ingresos, de la demanda y del empleo, mientras la economía de Estados Unidos solo comenzó su recuperación nueve meses después.

El día de la toma de posesión respecto al año anterior, las remesas familiares fueron $10 \%$ menores, las exportaciones $16 \%$ y las importaciones $29 \%$. El producto interno bruto (PIB) se redujo ese año 4,6\%, el déficit fiscal se incrementó al 5,6\% y la deuda pública al $53 \%$

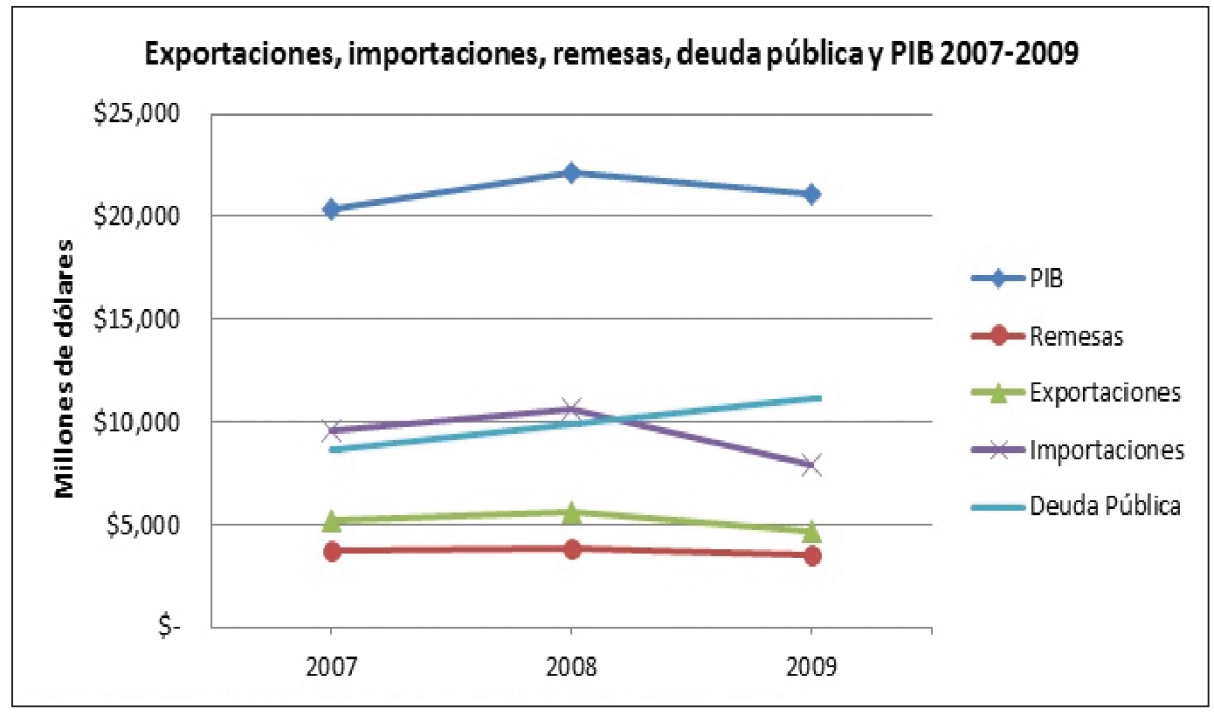

Fuente: Elaboración propia con base de datos del BCR y el Ministerio de Hacienda. 
Los homicidios dolosos aumentaron $40 \%$ en el primer semestre del 2009 respecto al 2008, para un aumento de la tasa anual de 36\%, incrementándose de 55 a 72 por cien mil habitantes, de 3.179 homicidios en el 2008 a 4.349 en el 2009.

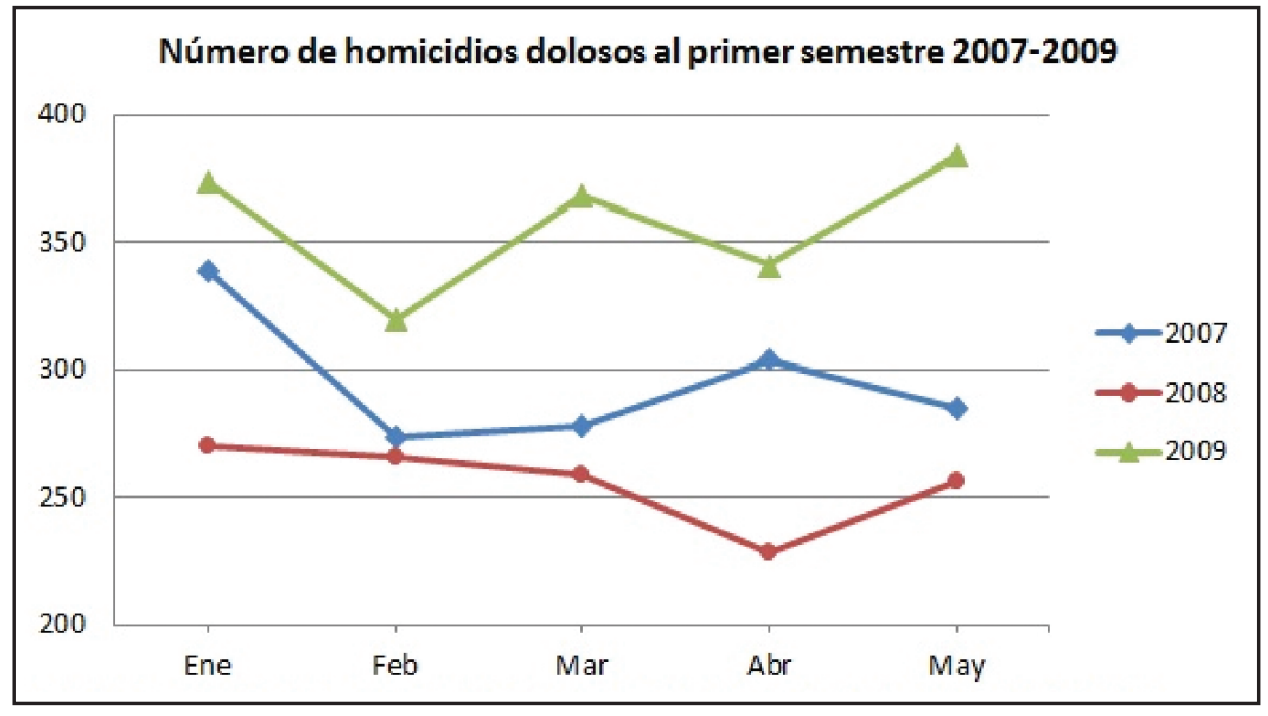

Fuente: Elaboración propia con base de datos del Observatorio Centroamericano sobre violencia.

El gasto en salud en el 2008 fue del 1,14\% del PIB (frente al $6,4 \%$ en Latinoamérica) y $7,6 \%$ del presupuesto nacional. El sistema de salud heredado se caracterizó por la baja inversión en salud pública y la baja cobertura de la red de servicios, de medicamentos, déficits de personal, e infraestructura y equipos inadecuados y obsoletos.

El gasto en educación en el 2008 fue 2,78 \% del PIB (frente a $7,3 \%$ en América Latina) y $18,4 \%$ del presupuesto nacional. $27 \%$ del grupo en edad escolar se encontraba fuera del sistema, la tasa de deserción era de 6,2\%, la tasa de repitencia global de $4.9 \%$, la nota promedio global real de la Prueba de Actitudes y Aprendizaje para Egresados de Educación Media (Paes) fue de 4.99. Las nuevas autoridades encontraron ausencia de estudios que orienten la creación de carreras universitarias según las necesidades del país, gran atraso en la enseñanza de las ciencias, matemáticas y lenguaje en todos los niveles, limitado desarrollo del arte, la cultura, la recreación, el deporte y la investigación científica, y una falta de vinculación de la escuela con la comunidad.
En síntesis, el gobierno de Funes heredó una enorme deuda social acumulada en un país sin institucionalidad y con alta polarización política y conflictividad social agravadas por la crisis, volviéndose el diálogo y la negociación un recurso obligado del nuevo Gobierno.

En lo político, las tensiones del presidente y su equipo con la dirigencia del FMLN se agudizaron con la elección del Gabinete de Gobierno, de los directores de las instituciones autónomas y de algunos embajadores y con la política exterior, que subrayó su identificación político-ideológica y alianza estratégica con Lula y Obama, no con Castro y Chávez. Aunque sin mayoría política en el parlamento, su equidistancia con el FMLN, su relación con el expresidente Saca y la división de la derecha, y su gran popularidad incrementada por los tres factores mencionados, le darían un mayor margen de maniobra para comenzar a gobernar.

Pero, al conocer con mayor profundidad la cruda situación heredada, el presidente no informó a la ciudadanía oportunamente y con suficiente claridad de la gravedad de la 
situación, lo que fue aprovechado por sus adversarios, poco tiempo después, para responsabilizarlo del deterioro de la situación nacional. Para algunos personeros de la derecha “... las cosas estaban bastante bien hasta que llegaron estos izquierdistas" ... 0, más bien, "desde los últimos dos años de Saca y el primero de Funes y el FMLN...".

La tormenta perfecta que le cayó a Funes el día siguiente del triunfo electoral y el entrampamiento perfecto con el que el presidente inició su nuevo gobierno mostraron sus limitados márgenes de maniobra de partida, determinando su característica principal: gobierno de contención de la crisis económica, social y política.

\section{El Gobierno y la economía. Desempeño y perspectivas}

Pero el nuevo gobierno tenía una importante agenda de reformas del sistema económico, social y político-institucional e intentaría hacer ambas cosas, contener la crisis e impulsar la reforma del sistema, partiendo de limitados recursos y de un alto endeudamiento, de una mayoría política precaria y de una situación internacional marcada por la crisis económicofinanciera y la disminución de la cooperación al desarrollo. En este contexto analizaremos su desempeño de junio 2009 a febrero 2011.

Pese a la compleja situación heredada, el Gobierno: 1) Ha contenido parcialmente la crisis económico-social y la crisis de seguridad pública; 2) Ha impulsado la refundación de la política económica, social y de seguridad, poniendo las primeras bases de un nuevo modelo político-institucional y económico-social esbozado en el Plan Quinquenal de Desarrollo 2010-2014; 3) Ha logrado un sólido posicionamiento interna- cional de amplia interlocución y credibilidad en función de intereses nacionales y centroamericanos.

El Gobierno le ha apostado a lo social con más de lo que puede y tiene, fijándole la crisis fiscal límites insuperables. No es un tema de voluntad política sino de recursos. El Gobierno está reestructurando la banca de fomento suministrándole 200 millones de dólares cuyo multiplicador generaría varios cientos de millones más de créditos a la pequeña y mediana agricultura e industria, viabilizando el Plan de Agricultura Familiar y el Plan Estratégico de la CONAMYPE. El Plan Integrado de Economía contribuirá, en el mediano plazo, a una mayor competitividad y a una mejor inserción internacional; y el Plan de Turismo tiene gran potencialidad de generación de empleo e ingresos.

La decisión de la ANEP de no discutir un pacto fiscal en el Consejo Económico-Social (CES) llevaría al Gobierno a presentar un borrador de ley de reforma fiscal para su aprobación en el 2011 con el apoyo de una parte del CES. La confrontación gobierno-gran empresa privada, las proyecciones de debilidad de la economía nacional y la incertidumbre sobre una eventual victoria del FMLN en las elecciones legislativas del 2012 y presidenciales del 2014, refuerzan los pronósticos de escaza inversión privada. Este es el gran talón de Aquiles, cuya superación es condición necesaria -no suficiente- de la sostenibilidad del crecimiento y del pago de las deudas pública y social, y de cualquier progreso.

Después de veinte meses de gobierno, la situación y perspectivas económicas son de pronóstico reservado, sin que se vislumbre una clara inflexión y mejoras sustanciales. Los índices per cápita de crecimiento económico y de creación de empleo seguirán siendo negativos o ínfimos en los próximos años, mientras los déficits comercial y fiscal y el endeudamiento público están llegando a los límites máximos permisibles, limitando la política social y la lucha contra la pobreza. 


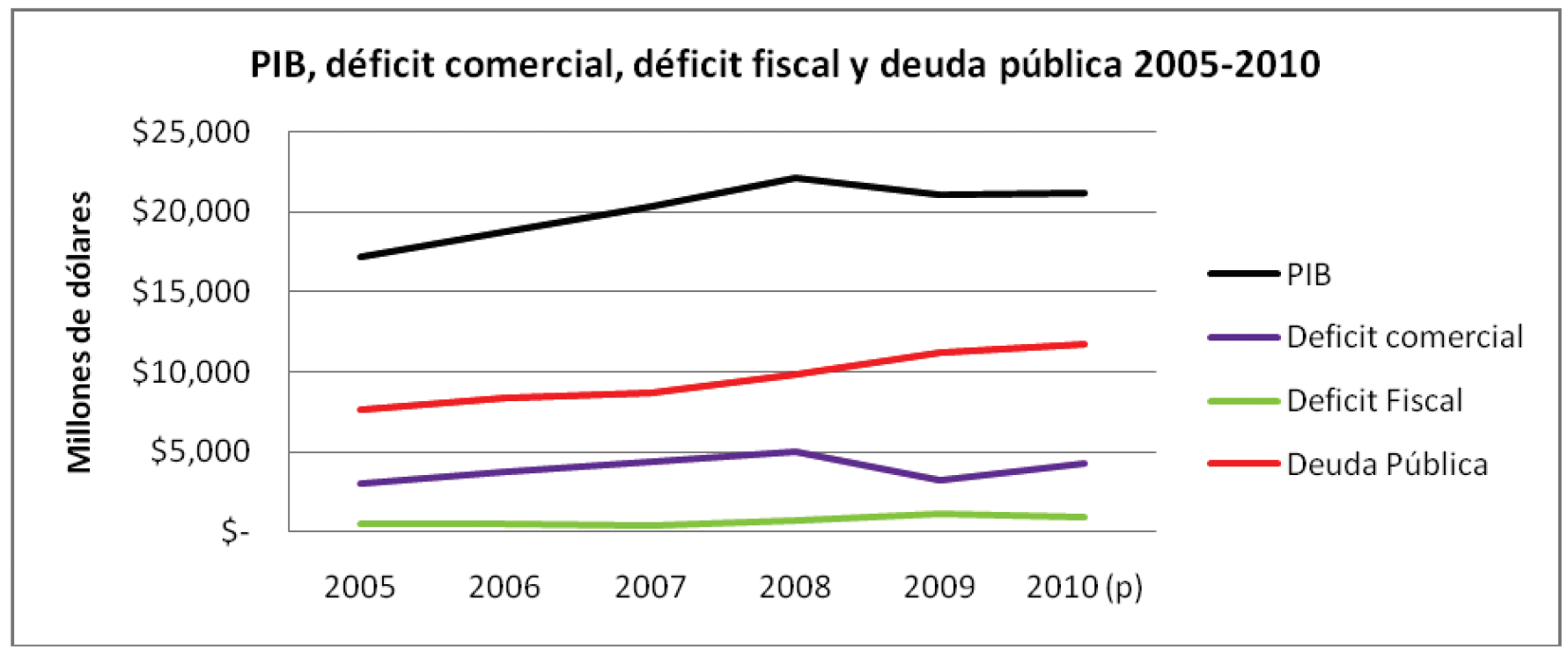

Fuente: Elaboración propia con base de datos del BCR y el Ministerio de Hacienda.

La ejecución en el 2011 de \$770.5 millones de dólares de inversión pública $(\$ 556,2$ millones para obras de infraestructura y \$204.3 millones para capital humano), las nuevas políticas de agricultura familiar y emprendurismo rural y de fomento de la pequeña y mediana industria, los altos precios internacionales del café y el repunte de la construcción en la economía de Estados Unidos, deberían tener un impacto positivo en el crecimiento y los ingresos públicos, contrarrestados por los altos precios del petróleo y de los alimentos. No obstante, la proyección gubernamental estimada de $2.5 \%$ de crecimiento y de $2.2 \%$ del Banco Centroamericano de Integración Económica (BCIE) contrastan con el 1\% de varios analistas. Un crecimiento del $2 \%$ apenas superaría el crecimiento poblacional estimado en $1,6 \%$, sin representar un punto claro de inflexión, a dos años y medio de concluir su mandato y a dos meses y medio de las elecciones legislativas y municipales. Con un crecimiento del $2 \%$ en los próximos años, la deuda pública total podría superar el 62\% del PIB en el 2015, según el Fondo Monetario Internacional.

El Gobierno deberá priorizar la ejecución de medidas de generación de ingresos fiscales y de contención del gasto para disminuir la perspectiva de una crisis de insolvencia después de las elecciones del 2012. Aunque el apoyo político de Obama a Funes sabemos que evitaría el default.

La visita del presidente Obama a El Salvador, la última semana de marzo 2011, será fundamental para la estrategia de seguridad nacional/regional y la concreción de una comisión contra la impunidad en Centroamérica, y tanto o más para sostener y mejorar la situación económica y social al incluir a El Salvador como uno de los cuatro países en el mundo el único en Latinoamérica- con el que Estados Unidos impulsará la Sociedad para el Crecimiento. Esta iniciativa estudiará la paradoja salvadoreña (uno de los países que mejor cumplió con las recomendaciones del Consenso de Washington pero que ha sido incapaz de generar inversión nacional y extranjera, y crecer) y apoyará una estrategia más integral para impulsar el crecimiento en los próximos años.

El margen de maniobra económico y fiscal-financiero que le queda al gobierno hasta el final de su gestión es muy estrecho. Mayor endeudamiento -apadrinado políticamente en los organismos multilaterales financieros- y sustanciales pa- 
trocinios y donaciones serán necesarios de Washington para mantener y mejorar un poco la situación hasta el final del mandato del Gobierno de Funes: renovación del TPS, aprobación de una segunda fase del Fomilenio, la Iniciativa (Bridge (por sus siglas en inglés) Fondos de Inversión para el Desarrollo Sostenible y el Emprendurismo ${ }^{5}$ y la plena incorporación inmediata del país a la Sociedad para el Crecimiento con financiamiento internacional, respaldos y donaciones diversas. Esta podría ser la génesis del surgimiento de una nueva matriz empresarial para la creación de la base productiva y exportadora que necesitamos.

Washington y el presidente Funes podrían demostrarle al mundo que en El Salvador la alianza con Lula/Obama habría dado muchos mayores beneficios a mucho menor costo que la alianza con Chávez y el Alba. Vaya ironía de la historia. El FMLN nunca imaginó que la viabilidad financiera del programa social y económico de su gobierno dependería, de inicio a fin del mandato, del apoyo de los "nefastos organismos multilaterales financieros" y del "imperialismo yanki". Gracias al acertado posicionamiento nacional e internacional del presidente, que tiene con Washington una original y efectiva palanca negociadora, su matrimonio de conveniencia con el FMLN, aliado estratégico de Castro, Chávez y Ortega.

\section{Confrontando y superando el entrampamiento perfecto}

Este entrampamiento perfecto no puede ser confrontado y superado con las visiones, enfoques y paradigmas tradicionales, ni con la reproducción del anacrónico y nefasto bipartidismo polarizante. Nada sería más provechoso para el país que la refundación democratizadora y modernizadora de ambos proyectos políticos o el surgimiento de un proyecto alternativo que lidere la implantación del nuevo modelo de desarrollo político, económico y social, que exige la construcción del futuro que merece El Salvador. Lo que el país requiere es un liderazgo que, con una nueva visión y estrategia, saque al país de la crisis y lo enrumbe a la transformación democrática y al desarrollo integral en este complejo y profundo cambio global de época.

Para salir de este entrampamiento casi perfecto se requiere una nueva visión del desarrollo que, partiendo de las potencialidades de El Salvador, lo inserte más y mejor en Centroamérica y el mundo. Dos décadas del orden político y económico de la post guerra están llegando a su fin, sin que haya surgido todavía su reforma para enfrentar los rezagos del siglo XX y los desafíos del XXI.

La nueva visión tiene que ser democrática, social, productiva, competitiva y global, centrada en la nueva sociedad mundial del conocimiento y en el desarrollo científico-tecnológico. Su punto de partida es priorizar la producción de riqueza y su mejor distribución, y profundizar y consolidar la democracia y la institucionalidad en un mundo global. El cambio cultural hacia la creación de riqueza, la estabilidad y la certidumbre de mediano y largo plazo, y la cooperación y concertación nacional y subregional están a la base de esta visión y perspectiva. Quitar los obstáculos y amarras a la inversión, la competencia y la obtención de ganancias son condiciones esenciales del modelo en el marco del respeto estricto a las leyes.

El punto de partida de la nueva visión es asumir que es imperativa una inserción competitiva a la globalización, que per-

\footnotetext{
${ }^{5}$ Programa que funcionaría a traves de emisiones de bonos respaldados por el Gobierno de los Estados Unidos con el apoyo de la banca privada que opera en el país. El gobierno salvadoreño ha presentado al de los Estados Unidos una lista de varios proyectos por un monto de 1000 millones de dólares para financiar diversos proyectos de infraestructura.
} 
mita transformar paulatinamente la estructura productiva y exportadora de bienes y servicios para acelerar el crecimiento. Esto posibilitaría la superación de los déficits comerciales y fiscales, la generación de empleos, de salarios e ingresos familiares, las ganancias empresariales para reinvertir y crecer, y los ingresos fiscales para afrontar progresivamente el pago de la deuda pública, social, medioambiental y de infraestructura. Esto solo será posible con una nueva visión y estrategia que cree las condiciones político-institucionales que permitan instalar este nuevo modelo de desarrollo.

Es imperativo el conocimiento de las realidades de la globalización y de la revolución científico-tecnológica en pleno siglo XXI y sus implicaciones para la democracia y el desarrollo de las naciones centroamericanas en el complejo escenario de aceleradas transformaciones globales. Y lo es aún más para las fuerzas de la democracia y de la modernidad, que deberían convertirse en los sujetos de la transformación requerida. El mundo cambió aceleradamente en los últimos veinte años, y aún más lo hará en los próximos decenios. Consecuentemente, el futuro de nuestro país no puede ser rehén de los liderazgos políticos, empresariales e intelectuales cuyo pensamiento quedó rezagado en la segunda mitad del siglo pasado.

\section{La agenda de transformaciones pendientes}

\section{Las transformaciones político-institucionales}

En su dimensión político-institucional, se tendrían que impulsar, al menos, las siguientes reformas:

1) Transformación del sistema electoral y del sistema de partidos mediante las reformas e implantación de leyes que aseguren su democracia e institucionalidad interna, el control de sus fuentes de financiamiento, la formación de sus militantes y dirigentes para mejorar su visión del país y del mundo, así como su preparación para ejercer la función pública. Asimismo, se deberá cumplir con la resolución de la Sala de lo Constitucional sobre las candidaturas no partidarias y el sistema de listas abiertas.

2) Transformación del Órgano Judicial para garantizar que haya tanto pronta y debida justicia para todos, así como seguridad jurídica para la inversión y los negocios.

3) Transformación de la Corte de Cuentas para asegurar la probidad de los funcionarios públicos en el uso de los recursos del Estado y la erradicación de la corrupción.

4) Reformas institucionales que minimicen el tiempo y los requerimientos para iniciar y ampliar nuevas empresas productivas y aseguren el cumplimiento de sus responsabilidades tributarias.

5) Reformar y fortalecer el sistema de organización y defensa de los legítimos derechos de los trabajadores; impulsar la formación y capacitación permanentes de sus líderes sindicales y de los trabajadores; asegurar la democracia interna y la transparencia en la vida de las organizaciones de los trabajadores; mejorar las condiciones ambientales y de seguridad de los centros de trabajo; promover nuevos tipos de relaciones obrero-patronales de cooperación; conciliar las reivindicaciones salariales con las exigencias de productividad y calidad de las empresas en el ámbito nacional, regional y global.

6) Promoción de la cultura democrática en el sistema educativo y los medios de comunicación social. 
7) Otras reformas jurídico-institucionales sobre hacienda pública (sistema tributario y fiscal, administración financiera del Estado), descentralización administrativa y gobiernos locales; servicio civil, etc.

\section{Las transformaciones económico-sociales}

En su dimensión económico-social, el nuevo modelo tendría que centrarse en la creación de condiciones atractivas para estimular la inversión nacional y extranjera, promoviendo la incorporación y difusión de la innovación y el progreso técnico para posibilitar el crecimiento de la producción nacional diversificada. Esta sustituiría importaciones, abastecería el mercado interno y multiplicaría la exportación de bienes y servicios de mayor valor agregado y productividad, creando más y mejores empleos y salarios, y sacando sostenidamente a un número cada vez mayor de familias de la pobreza.

Se trata de pasar de un modelo de consumo y considerable estancamiento social a uno de acumulación y progreso sostenido económico-social. Los tres ejes vertebrales complementarios de la estrategia deberán ser:

1) El aumento de la productividad de los pobres mediante políticas de fomento a la agricultura familiar, el emprendurismo rural y a la micro, pequeña y mediana industria, incorporando progresivamente a la legalidad al sector informal.

2) La creación cada vez mayor y más competitiva de riqueza, liderada por la inversión y tecnología extranjera para las exportaciones al mercado mundial de grandes y medianas empresas abastecidas progresivamente de bienes y servicios producidos por pequeñas, medianas y grandes empresas de la subregión. Las inversiones entre empresarios internacionales y nacionales serán fundamentales.

3) Fortalecer las procuradurías de la defensa del consumidor, de las superintendencias de electricidad y comunicaciones, de competencia y del sistema financiero.

Si bien muchas de estas tareas deberán de ser enfrentadas por el Estado en coordinación con el sector privado, hay una limitación de conocimientos, organización, recursos y tiempo para la innovación tecnológica y para estar en condiciones de penetrar los nichos específicos de diferentes mercados a escala internacional, así como existen limitaciones de recursos para la inversión multimillonaria en infraestructura, particularmente en puertos, aeropuertos, carreteras, ferrocarriles, redes de fibra óptica, etc. Esto nos conduce al papel crucial de la inversión y tecnología extranjera y a la estrategia y acuerdos entre Estados, tanto para respaldar y promover a grandes y múltiples inversionistas como para llegar a acuerdos de financiamientos concesionarios a largo plazo, donaciones y subsidios para financiar y construir la infraestructura necesaria que necesitará para el nuevo modelo de crecimiento e inserción competitiva a los mercados internacionales.

En efecto, no podemos esperar tener los excedentes fiscales necesarios para poder financiar dicha infraestructura, precondición de la inversión y el crecimiento del modelo por impulsar, porque ni los llegaríamos a tener con el actual modelo y, en el caso ilusorio que lo fuese, lo sería después de varias décadas para poder disponer de los recursos, financiarla y construirla. Para entonces, literalmente, nos habría dejado la historia. Dicha infraestructura es condición fundamental para 
atraer inversión y tecnología extranjera, crecer alta y sostenidamente y generar los excedentes fiscales para financiar el desarrollo social.

Pero El Salvador y Centroamérica tienen algunas ventajas y oportunidades importantes para llegar a estas alianzas estratégicas con otros Estados, para promover inversiones público-privadas y la inversión extranjera sostenida en las próximas décadas.

\section{Ventajas y oportunidades de El Salvador y Centroamérica para un nuevo modelo de crecimiento e inserción competitiva inter- nacional}

Hemos identificado al menos diez ventajas y oportunidades principales:

1) Ubicación geográfica y geocomercial. Entre las principales resaltan la ubicación geográfica y geocomercial entre el Norte y el Sur, el Pacífico y el Atántico, en un etapa histórica que profundiza la reubicación de la producción en función de los grandes mercados y el abaratamiento de los costos productivos y de transporte. De particular importancia es el mercado de Estados Unidos, Canadá y México en función de los flujos de transporte marítimo y comercio asiático y europeo respecto a la costa oeste de Estados Unidos, considerando que aún con la ampliación en curso, el canal de Panamá no dará abasto para cubrir en flujo y tiempo el incremento del transporte y carga proyectado en las próximas décadas.

2) El puerto de Cutuco en construcción, necesitándose la ampliación de Puerto Cortez en el Atlántico hondureño. Asimismo, el puerto de Acajutla ampliado y modernizado desempeñaría un papel fundamental. Ambos puertos y el Puerto en el Caribe hondureño constituirían el triángulo que uniría al Pacífico con el Atlántico a través de canales secos con supercarreteras $y / 0$ ferrocarriles de alta velocidad para transportar los contenedores de los barcos PANAMAX que llegarían a dichos puertos, en tiempos y costos menores a los del Canal de Panamá.

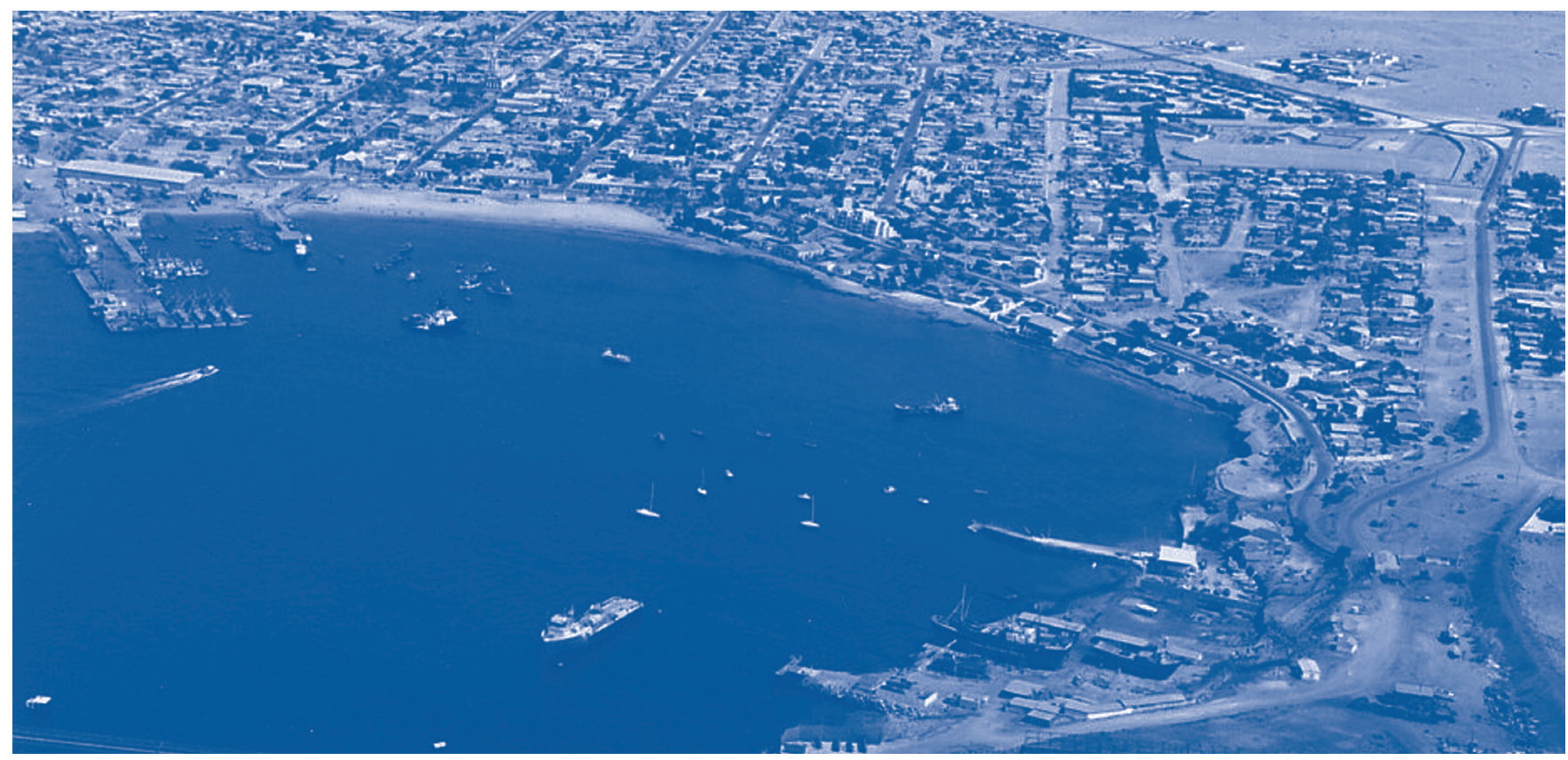


3) Crear una carretera y frontera directa entre El Salvador y Nicaragua en el golfo de Fonseca, entre el punto más cercano a la islas de Meanguerita y Meanguera hasta los farallones a pocos metros de Cosigüina. Dicho puente colgante se financiaría con peajes que financiaría una concesión de 30 a 40 años con empresas internacionales, potenciando el comercio y la inversión entre ambos países, y ampliando la conectividad y espacio económico comercial del canal seco entre el Pacífico y Atlántico.

4) La carretera Longitudinal del Norte sería una de las vías del canal seco que uniría dichos puertos entre ambos océanos.

5) Un buen sistema de carreteras que deberán ampliarse y mejorarse.

6) Un buen aeropuerto y líneas áereas con acceso eficiente a las principales ciudades de Centroamérica, México, Estados Unidos y Canadá.

7) Un sistema de telefonía fija y móvil moderno, de los mejores en Latinoamérica, que necesita una mayor regulación y supervisión para bajar precios y abusos diversos.

8) Un sistema financiero privado con altos niveles de profundidad y eficiencia, que necesita ser animado y urgido a apoyar la actividad productiva. Y una nueva banca de fomento que entrará en funcionamiento en la segunda mitad del 2011.

9) Tratados de libre comercio con Estados Unidos, México, Panamá, Chile, Taiwán y Canadá (en un futuro próximo).Además de un próximo acuerdo de asociación con la Unión Europea. Estos tratados son fundamentales para la atracción de inversiones extranjeras de esos países con miras a la exportación a los mercados de Norteamérica.

10) Una propuesta de conformación de una plataforma logística y de servicios especializados, como una apuesta estratégica para el desarrollo nacional impulsada por la Comisión Nacional de Desarrollo con diferentes estudios especializados e identificación de oportunidades y recursos diversos.

El Salvador es percibido internacionalmente como el país que está en mejores condiciones de liderar la refundación democrático-institucional y una mejor reinserción para el desarroIlo económico y social en la nueva economía internacional. El rumbo de la "Centroamérica del Norte" está estrechamente vinculado con el rumbo y características de un nuevo modelo de desarrollo liderado por El Salvador en el CA-4.

\section{Hacia una nueva visión para la transforma- ción de El Salvador en la primera mitad del siglo XXI}

El punto de partida es crear las condiciones de financiamiento, asistencia técnica y apoyo para promover inversiones en aquellas actividades rentables ya conocidas del sector agropecuario, agroindustrial y de producción de bienes y servicios diversos de pequeñas, medianas y grandes empresas que abastezcan los mercados locales, sustituyendo importaciones y abasteciendo la demanda potencial centroamericana e internacional.

Pero el enfoque prioritario de la estrategia parte del imperativo de una inserción competitiva a la globalización, que permita transformar paulatinamente la estructura productiva y exportadora de bienes y servicios para acelerar y sostener 
el crecimiento. Esto posibilitaría la generación de empleos; de salarios e ingresos familiares crecientes; las ganancias empresariales para reinvertir y crecer; la superación de los déficits comerciales y fiscales; y los excedentes fiscales crecientes para financiar la deuda social, infraestructural y ambiental y disponer de los recursos para afrontar los desastres naturales y las crisis económicas y financieras internacionales. Dichos excedentes fiscales necesarios para financiar esos requerimientos, superarían los $\$ 100$ mil millones de dólares en las próximas tres décadas. Solo pensando y actuando en grande y produciendo y distribuyendo mucha riqueza sería esto posible.

Necesitamos entonces una nueva visión y una estrategia que creen las condiciones político-institucionales que permitan instalar sin tregua ni pausa este nuevo modelo de desarrollo. Esto requiere, como complemento indispensable, una estrategia de integración y asociación acelerada con el resto de las naciones de la región, que haga de Centroamérica un centro de transporte, carga y distribución logística; un centro estratégico de inversiones productivo-exportadoras y comercial-abastecedoras entre el Pacífico y el Atlántico, que sea el eje articulador y portaviones principal de la transformación sostenida de la región en las próximas décadas.

El fortalecimiento y dinamismo de las economías centroamericanas es un eje fundamental en el crecimiento de la demanda y de las exportaciones como base de una inserción más amplia a la economía global. Pero la gran apuesta se tendría que centrar en los mercados internacionales, comenzando por aquellos de los que Centroamérica ya dispone, o dispondrá próximamente, de tratados de libre comercio o de tratados de asociación y cooperación (México, Chile, Estados Unidos, Europa, Canadá), complementándolos con una estrategia de atracción de inversiones y tecnología de Brasil, Japón, China, India y los llamados tigres asiáticos.
Las pequeñas y medianas empresas y las cooperativas, deberían ser apoyadas y potenciadas para estar en condiciones de proveer bienes y servicios crecientes a las medianas y grandes empresas exportadoras, con encadenamientos productivos hacia adelante y hacia atrás. Adicionalmente, la expansión económica resultante ampliará el crecimiento de la demanda de bienes y servicios diversos, que deberían abrir oportunidades adicionales al mercado interno.

La atracción de recursos humanos calificados salvadoreños y centroamericanos residentes en el exterior y de inversionistas salvadoreños y centroamericanos radicados en Estados Unidos, Canadá, Australia y otros países deberá ser priorizado. Esta visión y estrategia conlleva, evidentemente, transformaciones en: la educación, adquisición y difusión del conocimiento científico-tecnológico; la infraestructura y la conectividad; la producción de energías limpias y eficientes y la gestión y protección medioambiental; la cultura laboral, empresarial y cívica hacia la producción sostenida de riqueza; la reforma y fortalecimiento de las instituciones nacionales y de la integración centroamericana.

El conocimiento de nuestra historia, el fortalecimiento de nuestra identidad nacional y centroamericana, la promoción y difusión del arte y la cultura deben tener un lugar prioritario en el nuevo modelo y en la nueva etapa de nuestra historia. Las alianzas público-privadas tendrían que jugar un papel central en las inversiones, dinamizadas principalmente por las inversiones privadas sostenidas que junto, a las reformas fiscales paulatinas, posibilitarían el crecimiento y la reconstrucción progresiva de las finanzas públicas, dotando de viabilidad estratégica a los Estados de la región.

Sin crecimiento económico sostenido no habrá empleo e ingresos -familiares y fiscales-, ni redistribución y desarrollo 
social, mientras la violencia encontrará mayores espacios y legitimidad para avanzar. Deberán priorizarse el crecimiento económico y la transformación social, pero subrayando el fortalecimiento de la democracia y la institucionalidad, tan fundamentales para la convivencia social, la estabilidad política y la inversión privada.

El gran imperativo nacional es desmontar el entrampamiento perfecto y transformar a El Salvador y Centroamérica, progresiva y sostenidamente, en las próximas décadas.

El sujeto histórico de dicha transformación tendría que organizarse y desarrollarse progresivamente, conllevando el reagrupamiento y fortalecimiento de las fuerzas democráticas y de la modernidad para estar en condiciones de asumir el impulso de esta estrategia, para la creación competitiva y sostenida de riqueza a escala global, así como su mejor redistribución nacional y regional.

Pero El Salvador tiene un interés, una misión y una responsabilidad particular en Centroamérica y en especial con las naciones vecinas (Guatemala, Honduras y Nicaragua), con las que integra el CA-4, su espacio político y económico natural. El Salvador tiene más condiciones y posibilidades de liderar la refundación y revitalización democrático-institucional y económico-social de Centroamérica.

El liderazgo de El Salvador, a partir de su propia refundación, ejemplo y cooperación democrático-institucional y de su propio desarrollo nacional/regional de alto crecimiento y distribución sostenidos, es fundamental para la transformación y estabilidad de Centroamérica, particularmente de los países integrantes de la subregión del centro al norte de Centroamérica: Nicaragua, Honduras, El Salvador y Guatemala .

En un nuevo escenario de transformacionales, en el plano internacional y regional, el diseño, consenso e implantación de un nuevo proyecto político y de desarrollo nacional/regional que tenga espacio, viabilidad y respaldo, constituye el gran desafío de nuestro tiempo.

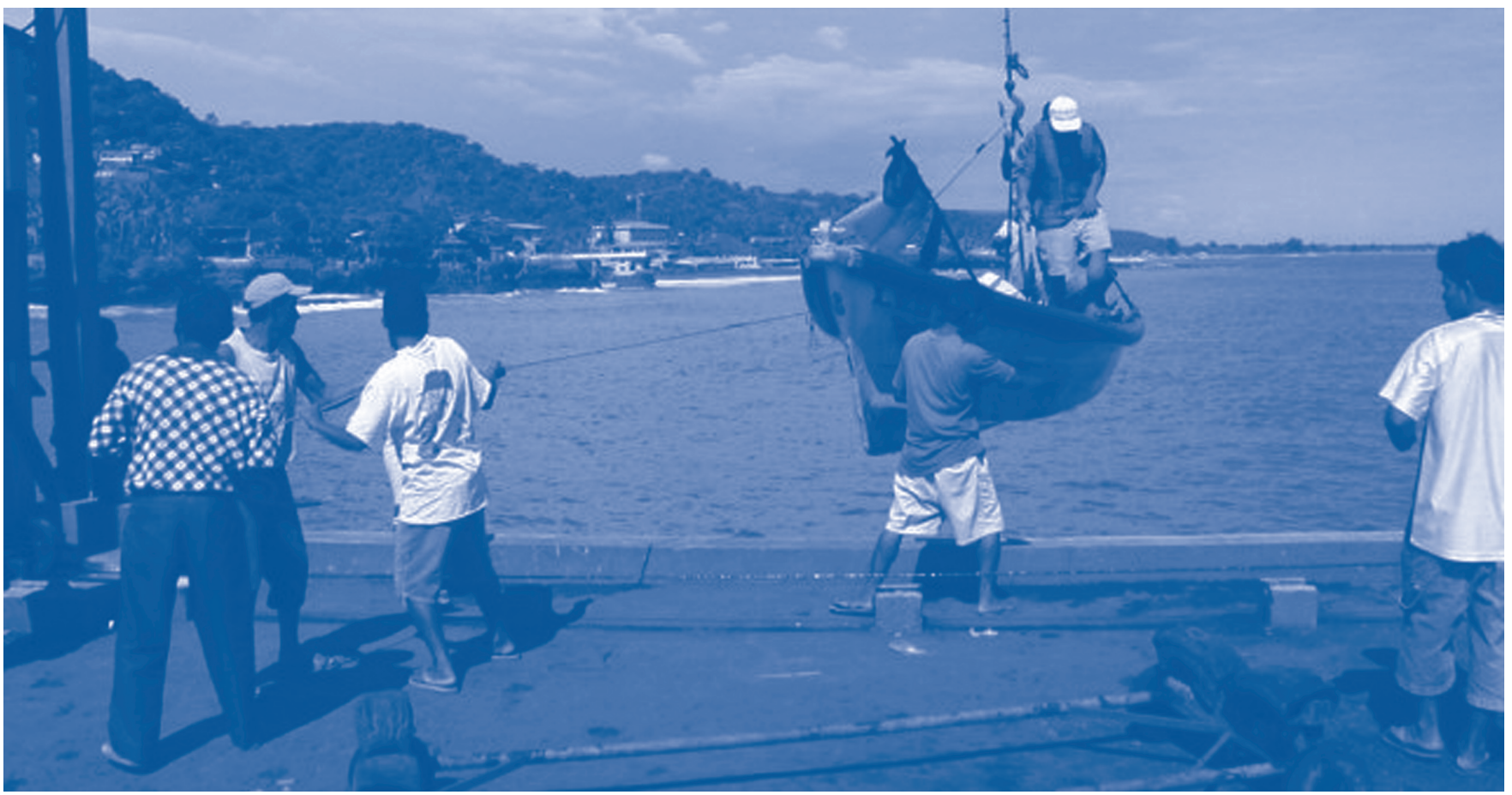

